\title{
Effect of Progressive Muscle Relaxation Technique on Blood Pressure, Anxiety and Stress among Elders in Assisted Living Facilities
}

\author{
Josphen Youssef Gaied Abdelsaid, Assistant Lecturer \\ Gerontological Nursing, Faculty of Nursing, Alexandria University
}

\author{
Moshera Mostafa El-Geneidy, Professor \\ Gerontological Nursing, Faculty of Nursing, Alexandria University
}

Magdala Habib Maximos, Professor

Psychiatric Nursing and Mental Health, Faculty of Nursing, Alexandria University

Reham Magdy Mohamed Abd El-Salam, Assistant Professor
Gerontological Nursing, Faculty of Nursing, Alexandria University

\begin{abstract}
Elders in assisted living facilities are exposed to many stressors, so the gerontological nurse has an important role to implement many strategies and techniques. Progressive muscle relaxation $(P M R)$ is the most effective technique used to reduce high blood pressure, stress and anxiety. Objective: Determine the effect of PMR technique on blood pressure, anxiety and stress among elders in assisted living facilities. Setting: The study was conducted in three governmental homes Dar El Hanna, Dar El Wedad, and Dar El Hedaya. Subjects: They comprised 60 residents. These were divided into two equal groups: study 30 and control 30. Tools: Four tools were used to collect the data: Mini Mental Scale Examination, Beck Anxiety Inventory, Perceived Stress Scale and Older adults Socio-demographic and Clinical Data Structured Interview Schedule. Results: A significant difference was observed between the mean scores of BP, anxiety and stress levels of elders in the study and control groups after the implementation of the program. Conclusion: PMR technique has a positive effect on controlling blood pressure, anxiety and stress among older adults. Recommendations: The gerontological nurse should teach, encourage and motivate elders to perform PMR.
\end{abstract}

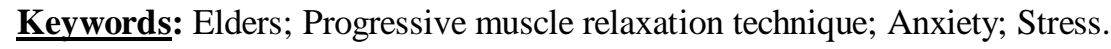

\section{Introduction}

It is reported that even with the best equiped facilities, and with the most skilled staff, the residential elderly home may not be able to offer a level of comfort and personal care that the elder may find in his own home ${ }^{(1,2)}$. Living in institutions for many years affects the elders's social, psychological, and physical wellbeing. This is mainly due to the elders ' separation from his family, home routine and presence of chronic diseases. Separation from the family members and home environment leads to the break of social contacts which may have a negative psychological and social impact on the elderly leading to stress, anxiety and high blood pressure. Also, the institution daily routine leads to limited social interaction, restriction of mobility, imposing schedule for performing ADLs, eating, bathing, sleeping these lead to elders' dependency, loss of identity, security and autonomy $^{(3,4)}$.

In addition to the presence of chronic diseases and comorbidities associated with aging requires continuous medical care, which the elder cannot afford due to limited financial resources. Institutionalization is associated with many psychological changes such as elders feeling of being rejected from their family, feeling of hopelessness, lack of confidence in oneself and others, and fear of becoming more dependent. All these factors affect the psychological, social, and physical 
status of elders and lead to increasing levels of stress, anxiety and blood pressure ${ }^{(5)}$.

Different studies revealed that stress, anxiety, and high blood pressure are prevalent among institutionalized elders. In USA, 2014, the prevalence of stress and anxiety was estimated to range between $5.5 \%$ and $10 \%{ }^{(3)}$. In Malaysia in 2015, the reported figures were $22.6 \%$ for stress and $8.7 \%$ for anxiety ${ }^{(6)}$. High figure $29 \%$ was reported from Kathmandu, Nepal; Asia 2016. In Cairo, Egypt 2013, stress and anxiety were reported to be prevalent among $36.4 \%$ of institutionalized elders ${ }^{(7)}$. In Alexandria, Egypt, in 2013 the reported figures of stress and anxiety were $33.4 \%$, and $30 \%$ respectively, while in 2015 stress and anxiety were reported to be prevalent, $30 \%$ and $14.2 \%$ respectively among institutionalized elders ${ }^{(8)}$. High blood pressure is associated with stress and anxiety. Stress in life cannot be avoided. Normal stress increases heart rates and prepares the body for a fight or flight response. In case of prolonged stress i.e. when the elder is unable to cope with stressors or when the stressor cannot be removed, it may lead to irritability, fatigue, headache, sleep disturbance, physical problems and high blood pressure. It is reported that prolonged stress and anxiety are the main risk factors for hypertension ${ }^{(9)}$.

Many studies reported the effect of different relaxation techniques in reducing stress, anxiety and blood pressure among these are meditation, Yoga, and progressive muscle relaxation (PMR) technique ${ }^{(10,11)}$.

Progressive muscle relaxation (PMR) is the simplest and most effective method to decrease muscle tension, reduce the level of stress, anxiety and lower blood pressure ${ }^{(12)}$.

It involves slowly tensing then relaxing each muscle group in the body. This increases self-awareness of the sensation associated with tension and, in turn, helps to identify and deal with the physical effects of every day stress. Moreover, PMR if regularly practiced by elders may help in the treatment of insomnia, anxiety and hypertension ${ }^{(13,14)}$.

In this respect, the gerontological nurses play an important role in decreasing elders' levels of stress, anxiety and blood pressure. This can be achieved by early identification of signs of stress and anxiety and by the application of appropriate interventions, in order to prevent the consequences of unrelieved stress and $\operatorname{anxiety}^{(15)}$.

However, few researches have been applied to determine the effect of PMR as a relaxation technique on elders' hypertension, anxiety and stress levels. So, this study will help to throw light on the effect of the application of progressive muscle relaxation technique on stress, anxiety and blood pressure levels.

\section{Aim of the Study}

The study aims to determine the effect of progressive muscle relaxation technique on blood pressure, anxiety, and stress levels among elders in assisted living facilities.

\section{Research Hypothesis}

Elders residing in assisted living facilities who receive progressive muscle relaxation technique exhibit lower anxiety and stress levels, as well as controlled blood pressure than those who do not receive it.

\section{Materials and Method}

\section{Materials}

Design: A Quasi-experimental research design was followed in this study.

Setting: The study was carried out in three of the six governmental elderly homes available in Alexandria namely Dar El Hanna for female elders, Dar El Wedad for both males and females, and Dar El Hedaya for males and females. The other three homes were excluded from the study in Dar Om El Nour none of the residents were fulfilling the inclusion criteria of the study. Dar El Hanan was closed at the time of data collection, and Dar El Saada refused to 
permit the researcher to interview the residents.

Subjects: The study included all elders residing in the above mentioned settings and fulfilling the following criteria: Aged 60 years and more, able to communicate effectively, with no or mild cognitive impairment, with mild or moderate anxiety, with mild or moderate stress, and with a blood pressure above $140 / 90 \mathrm{~mm} / \mathrm{Hg}$. The Epi info V.7.0 was used to estimate the sample size using the following parameters:

- Population size $=165$

- $\quad$ Expected frequency $=50 \%$

- Acceptable error $=10 \%$

- Confidence coefficient $=99 \%$

- $\quad$ Minimal sample size $=54$

The total sample size comprised 60 residents: These were divided into two equal groups: study 30 and control 30.

Tools: Four tools were used to collect the data:

Tool I: Mini Mental Scale Examination (MMSE)

The MMSE was developed by Folstein (1975). It was translated into Arabic by Elhusseini $(2008)^{(2)}$ and proved to be valid and reliable $(\mathrm{r}=0.82)$. The scale is used to assess the elders' cognitive status. The MMSE consists of 10 items covering 30 questions that investigate memory, orientation, attention and calculation, naming, repetition, registration, and language. The score ranges from 0 to 30 . A score from 24-30 indicates normal cognitive function, a score from 18-23 indicates mild cognitive impairment and a score from 0-17 indicates severe cognitive impairment.

\section{Tool II: Beck Anxiety Inventory (BAI)}

This scale was developed by Beck et al $(1988)^{(16)}$. It is used to measure the severity of an individual's anxiety. It was translated into Arabic by Hellmi (2012) ${ }^{(17)}$ and proved to be valid and reliable $(\mathrm{r}=0.79)$. The Beck Anxiety Index includes 21 items. Each item is rated on a 4-point rating likert scale where: "not at all bothered" is scored zero (0), "mildly but did not bother" (1), "moderately, it was not pleasant at times" (2), and "severely bothered" (3). Items are summed to determine the level of anxiety, with higher score reflecting greater anxiety of the study subjects. The BAI has a maximum score of 63 where anxiety levels are defined as mild ( 0 to 21 ), moderate (22 to 35 ) and score of 36 and above indicates a severe anxiety level.

\section{Tool III: Perceived Stress Scale (PSS)}

This scale was developed by Cohen $(1983)^{(18)}$ for the assessment of stress. It was translated into Arabic by "Abou El Seoud" $(2013)^{(19)}$ and proved to be valid and reliable $(r=0.72)$. This scale includes 14 questions. Each question is rated on a 5- point likert scale: "never" scored zero (0), "almost never" (1)," sometimes" (2), "fairly often" (3) and "very often" (4). The PSS has a maximum scored of 56, where stress levels are defined as mild score (0 to 18$)$, moderate (19 to 37 ) and severe (38 to 56).

Tool IV: Older adults Socio-demographic and Clinical Data Structured Interview Schedule

This tool was developed by the researcher based on relevant literature to collect the following information from the study subjects:

\section{A- Socio-demographic characteristics:}

Such as: age, sex, marital status, educational level, occupation before retirement and income.

\section{B - Clinical data:}

Such as: the presence of medical problems; onset and duration of the disease, treatment regimen, number and reason of previous hospitalization during the last year..

\section{Method}

- The necessary approvals to carry out the study were obtained from the responsible authorities namely; 
Minister of Social Solidarity to obtain the approval to carry out the study in the selected settings and director of each of the selected homes.

- The Arabic versions of tool I, tool II, and tool III were used in this study to assess the cognitive status, level of anxiety and stress respectively of the study subjects.

- The researcher measured the older adults' blood pressure using the same sphygmomanometer and stethoscope in order to identify those with high blood pressure (i.e. more than 140/90 $\mathrm{mmHg}$ )

- Tool IV the socio demographic and clinical data structured interview schedule of the study subjects was developed by the researcher.

- The researcher attended a training course on the application of the progressive muscle relaxation technique for three months in an accredited center namely "Farha center of Psychological Counseling and Self Training" in Alexandria.

- A pilot study was carried out on six elders selected from Dar Mohamed Ragab to assess the applicability, clarity and feasibility of the study tools, and necessary modifications were done accordingly. These elders were not included in the study subjects.

- A survey was carried out in three governmental elderly homes (Assisted living facilities) in Alexandria, in order to estimate the total number of residents in these homes and to calculate the minimum sample size to be included in the study. The result of the survey revealed that the total number of residents in these homes was 165; ( in 25 November 2017). The estimated minimum sample size was 54. The researcher included 60 residents in the study.
- All residents in the three selected governmental homes were interviewed by the researcher in order to identify those fulfilling the inclusion criteria; using Tool I (MMSE), Tool II (BAI), Tool III (PSS). As well, the blood pressure of each elder was measured to identify those with blood pressure above $140 / 90 \mathrm{mmHg}$.

- The researcher used to go on Saturday, Monday, and Wednesday weekly to Dar El Hanna and on Sunday, Tuesday, and Thursday to Dar El Wedad and Dar El Hedya. The researcher collected data in the afternoon for four hours, from $12 \mathrm{Pm}$ to $4 \mathrm{pm}$.

- Each elder included in the study was interviewed individually in his room to collect the necessary basic data.

- Progressive muscle relaxation technique was implemented individually in 12 sessions; (3days per week for 4 weeks). Each session took about 20 minutes; the average number of elderly interviewed and joined the program ranged from 7-10 elders per day.

- The program implementation:

- Before each of the sessions the researcher showed the participants a video of PMR technique, this helped to remind them of the technique.

- Also the researcher practiced the exercise with study elders in order to encourage and motivate them.

- The researcher observed the elder while performing the exercise to ensure that the exercises are done correctly.

- First session: The session included a brief introduction about the benefit and technique of the progressive muscle relaxation program followed by 
demonstration of the techniques. The first session included the following muscles: face muscles (forehead - eyes - mouth):

1- Forehead: raise the eye brows as high as they will go, as if the elder is surprised by something

2- Eyes: squeeze the eyes tight shut.

3- Mouth: open the mouth as wide as the elder can, as when yawning.

- The second session included the following muscles: arm and shoulder muscles (shoulders upper arms - and forearm):

1- Shoulder: tense the muscle of the shoulders by bringing the shoulders up towards the ears.

2- Upper arm: bring the right forearm up to the forearm up to the shoulder to "make a muscle".

3- Forearm: make a fist with the right hand

- The third session included the following muscles: Sternum exercises include: (the neckchest- abdomen):

1- The neck: face forward and then pull the head back slowly as though elderly was looking up to the ceiling.

2- The chest: push the shoulder blades back try to almost touch them together, so that the chest was pushed forward.

3- Abdomen: breathe in deeply, filling up the lungs and chest with air.

- The fourth session included the following muscles: Leg muscles include: (the hip - leg - foot):
1- The hip: tighten the right thigh by lifting the leg straight while the elder is sitting on the chair.

2- The leg: pull the right toes upwards to stretch the calf muscle.

3- The foot: curl the right toes downwards.

- Study subjects were evaluated before and immediately after the program implementation to assess anxiety level using tool II (Beck Anxiety Inventory), Stress level using tool III (Perceived Stress Scale) and Blood pressure level using the same sphygmomanometer and stethoscope. Subjects in the control group were evaluated twice at the same time of the study subjects. The evaluation of effectiveness of the proposed training was determined using the proper statistical analysis.

- Data was collected during a period of two months starting from the first of April to the end of May 2018.

\section{Ethical considerations:}

An informed consent was obtained from each study subject, after appropriate explanation of the study purpose. Study subjects' privacy and anonymity was respected and confidentiality of the collected data was assured. The possibility to withdraw from the study at any time was assured.

\section{Statistical Analysis}

Data were analyzed using "SPSS" software version 20. Comparisons between two groups were carried out using MannWhitney $U$ test for the quantitative variable while Chi-Square $(\chi 2)$ and Monte Carlo testes for qualitative variables. T-test was used to test association between two quantitative variables. Fisher's exact (FET) test was used for comparisons between the distributions of two qualitative variables. 


\section{Results}

\section{Part I: Socio-demographic characteristics and life style patterns of the study subjects:}

Table (1) shows the distribution of elders in the study and control groups according to their socio-demographic characteristics. The age of the participants ranged from 60 up to 89 , years with a mean age of $72.3 \pm 4.64$ years for those in the study group and 77.6 \pm 3.93 years for those in the control group. Females constituted $66.7 \%$ and $60.0 \%$ in the study and control groups respectively, and the rest $33.3 \%$ and $40 \%$ were males in the study and control groups respectively. Regarding the study subjects' level of education $20 \%$ in the study group and $23.3 \%$ in the control are illiterates and $23.3 \%$ and $16.7 \%$ respectively can read \& write. The rest in both groups had either primary or secondary or intermediate education. As for the elders' occupation prior retirement, it appears from the table that, more than one third of the study and control groups $(36.7 \%, 40 \%$ respectively) were housewives and the rest were either employees $26.7 \%$ and $40 \%$ or worker $26.7 \%$ and $3.3 \%$ and the rest $10 \%$ and $16.7 \%$ respectively had private jobs. The monthly income was reported to be adequate by $60 \%$ and $56.7 \%$ of the study and control groups respectively and for the rest in both groups it was inadequate. The majority of the subjects reported having children $(66.7 \%$ and $76.7 \%)$ in the study and control groups respectively; while the rest had no children. The duration of stay in the home, elders admitted for one to less than five years were $73.4 \%$ for the study group and $53.3 \%$ for the control. While the rest, $26.7 \%, 46.7 \%$ in both groups respectively, were admitted for five years and more.

\section{Part II: Clinical data:}

Table (2) shows the distribution of elders in the study and control groups according to the presence of other chronic diseases beside hypertension (which is one of the inclusion criteria). Cardiovascular or endocrine diseases (mainly DM) were reported by
$46.6 \%$ and $30 \%$ of the study group compared to $63.3 \%$ and $16 \%$ respectively for those in the control group. Neurological, musculoskeletal, and respiratory diseases were encountered in $23.3 \%, 16.6 \%$ and $13.3 \%$ respectively of the study group; compared to $26.6 \%, 6.66 \%$ and $10 \%$ respectively in the control group. The rest of the study subjects had other diseases such as GIT, renal and hematological diseases. It is also observed from the table that the main drugs consumed by elders in the study and control groups, beside hypertensive drugs, are hypoglycemics $23.4 \%$, anticoagulants $15 \%$, vitamins $13.3 \%$ and cortisol/hormones drugs $11.6 \%$ among study group; compared to $31.7 \%, \quad 18.3 \%, \quad 6.7 \%$ and $6.7 \%$ respectively among the control group.

\section{Part III: Effect of progressive muscle relaxation technique on levels of $B P$, stress and anxiety:}

Table (3) shows the comparison between elders in the study and control groups according to their blood pressure, anxiety and stress levels, before and after implementation of the progressive muscle relaxation technique. According to the inclusion criteria; all participants in the study and control groups suffer from high blood pressure (i.e. more than 140/90 $\mathrm{mm} / \mathrm{Hg}$.) After the implementation of the program, the BP of $90 \%$ of the study subjects decreased to less than 140/90mm/Hg; and only 3 elders (10\%) had still high blood pressure: the difference is statistically significant $(\mathrm{p}=0.000)$.while, In the control group $80 \%$ had still high blood pressure; and only six elders $(20 \%)$ had normal blood pressure with no statistical significant difference $(\mathrm{P}=1.000)$.

Concerning the anxiety level before the implementation of the program all the study subjects in study group had either mild or moderate anxiety level, $56.7 \%$ and $43.3 \%$ respectively, after the program those with mild anxiety increased to $76.7 \%$, and only 7 (i.e. $23.3 \%$ ) had moderate anxiety. The differences are not statistically significant. $(p=0.100)$. As regard the control group at the 
time of selection $60 \%$ had mild level of anxiety; and the rest $(40 \%)$ had moderate level of anxiety. After one month elders with mild anxiety decreased from $60 \%$ to $53.3 \%$ and those with moderate anxiety increased from $40 \%$ to $46.4 \%$; the differences are not statistically significant $(\mathrm{p}=0.561)$. Regarding the stress level, $80 \%$ of the study subjects had moderate level of stress before the implementation of the program and the rest $(20 \%)$ showed mild level of stress: while; after the program a slight improvement was observed among elders; where elders in the study group with mild level of stress $(20 \%)$ increased to $26.7 \%$. Those with moderate level of stress ( $80 \%$ before the program) decreased to $73.3 \%$ after the program. The difference is not statistically significant $(p=0.069)$. Concerning the control group the table shows that $80 \%$ of the elders had moderate level of stress and the rest $(20 \%)$ had mild stress, after one month, a drastic change was observed in the stress level of the control group. While those with moderate level of stress increased from $80 \%$ to $96.7 \%$ and one $(3.3 \%)$ had severe level of stress. The differences are not statistically significant $(p=0.107)$.

Table (4) shows the relation between the mean score of BP., anxiety and stress levels between study and control groups one month after the implementation of the program. The table shows a significant relation between the mean scores of BP, anxiety and stress levels of elders in the study and control groups after the implementation of the program $(\mathrm{P}=0.000,0.001$ and 0.001$)$ respectively. Comparing the mean scores among the two groups; the table shows: The mean score of systolic and diastolic blood pressure of elders in the study group is $130.17 \pm 6.884$ (systolic)

$96.83 \pm 7.484 \quad$ (diastolic)

compared to

$\underline{144.83 \pm 6.363 \text { (systolic) }}$

$83.00 \pm 9.523$ (diastolic) among those in the control group. The difference is statistically significant $\mathrm{P}=0.000$.

The mean score of anxiety level among the study group after the implementation of the program is $15.03 \pm 8.708$ compared to $22.53 \pm 8.148$ for the control group. The differences are statistically significant. $\mathrm{P}=0.001$.

Regarding the mean score of stress level of the study group is $21.13 \pm 7.253$ compared to $26.97 \pm 5.116$ for the control group. The differences are statistically significant $\mathrm{P}=0.001$.

Table (5) shows the relation between age and levels of Blood pressure, anxiety and stress among study and control groups after implementation of the program. Regarding the level of blood pressure the table shows that the age of participants affected significantly the mean score of the level of blood pressure among young elders aged (60 to less than 70) and high significant relation in those aged ( 70 to less than 80 years old). $\mathrm{P}=0.007$, and 0.000 respectively.

Regarding anxiety level the table also, shows that the age of participants affected significantly the mean score of the level of anxiety among those aged 60 to less than 70 and high significant relation was observed in those aged (70 to less than 80 years old). $\mathrm{P}=0.009$, and 0.000 respectively.

Concerning stress level, the table illustrates that the age of participants affected significantly the mean score of the level of stress among those aged 70 to less than 80 years old $(\mathrm{P}=0.004)$.

Table (6) shows the relation between sex and levels of blood pressure, anxiety and stress among study and control groups after implementation of the program. The table shows that the sex of participants affected significantly the mean score of the level of blood pressure, anxiety and stress among those males $p=0.000, p=0.049, p=0.007$ and females $\mathrm{p}=0.000, \mathrm{p}=0.019, \mathrm{p}=0.013$ in both study and control groups after the implementation of the program. 
Table (7) shows the relation between the level of education and levels of blood pressure, anxiety and stress among study and control groups after implementation of the program. Regarding the level of blood pressure the table shows that the level of education of participants affected significantly the mean score of the level of blood pressure among elders with different levels of education, while the anxiety level was not affected by the different levels of education of participants. On the other hand, the level of education of participants affected significantly the levels of stress among those were illiterate. $\mathrm{P}=0.042$.

\section{Discussion}

Older adults living in assisted living facilities are more at risk to develop stress and anxiety due to separation from their homes, family, friends, in addition to their exposure to different losses such as loss of power, spouse, significant others, job and change in health, loss meaning of life and fear of death. Moreover, stress and anxiety usually lead to increase in BP, decrease ability to perform ADLs and decrease feeling of wellbeing. Progressive muscle relaxation technique is reported to be a simple and effective measure used to reduce stress, anxiety and high $\mathrm{BP}^{(1)}$.

Therefore this study was conducted to determine the effect of progressive muscle relaxation (PMR) on stress, anxiety and blood pressure among institutionalized elders. The program achieved greater improvement in decreasing the levels of anxiety, stress and blood pressure (table 3, 4).

Stress, anxiety and blood pressure are associated with aging particularly among residents in assisted living facilities. This is probably due to expected deterioration in health status, increased dependency and separation from familial environment (table $1,2,5)$. This result is congruent with the study done in USA by Blazer DG (2003) ${ }^{(20)}$ which revealed that there is a positive relation between stress, anxiety levels and increasing of aging. While it is in contradiction with Drentea in 2000 who revealed that increase stress and anxiety occur in young-old (those 60 to less than70 years) because of their experience of retirement ${ }^{(20)}$.

The present study revealed that increase stress, anxiety and elevated blood pressure were more observed among female elders than males (table 1, 6). This may be because females are more emotional, more concerned about family members, have more worries about their future; in addition to the hormonal changes, i.e. decrease in estrogen level which leads to an increase in blood pressure. This result is in line with the findings of Carmen et al. in USA in $2012^{(21)}$ which revealed that women have consistently higher prevalence rates of anxiety and stress, but it is inconsistent with another study done by Fiske et al. (2012) ${ }^{(22)}$, who revealed that stress and anxiety are more prevalent in male elders because they have less coping skills to stress and anxiety than females.

In relation to the income, the results of this study revealed that lower levels of stress and anxiety are observed among elders with inadequate income (table 1). This may be due to their efficient coping with their resources, where those with limited financial resources may omit and neglect many unnecessary needs that may put them under stress or anxiety. On other hand, the present result contradicts those of Caron et al, 2011 in $\mathrm{USA}^{(23)}$ who revealed that inadequate monthly income was associated with increase stress and anxiety.

The present study results revealed that increase stress and anxiety was observed among elders who have children (table 1). This may be related to their worry about the future of their children and/or conflict relationship between family members as evidenced by older adults' subject who leave their homes and stay in assisted living facilities. The study done by (Zunzunequi et al, 2001) $)^{(24)}$ in India revealed that positive 
family tie and supportive family members lead to decrease stress and anxiety levels.

As regard the practice of exercise the present study showed that the majority of the studied elders who do not practice exercise reported increased levels of stress, anxiety and blood pressure, this result is congruent with other researches done by Burckhardt, Hanestad (2005) (25) in Australia who reported the positive effect of practicing exercise on the psychological and physical aspects, as decrease stress and anxiety levels and control of elevated blood pressure.

The duration of stay in assisted living facilities was associated with high stress and anxiety levels (table 1). This may be due to the effect of relocation stress syndrome and poor coping mechanisms. This result is congruent with a study done by (Morton and Lieberman 2012) ${ }^{(\mathbf{1})}$ in USA, which revealed that elders who are newly admitted into elderly homes experienced high levels of stress and anxiety especially in the first five years of institutionalization.

Regarding the effectiveness of the Progressive Muscle Relaxation (PMR) technique on levels of anxiety, stress and blood pressure, after the program implementation elders with mild anxiety increased to more than three quarters, this denotes the effect of PMR in decreasing anxiety level (table 3,4). These results are supported those of Sheetal Barde (2013) in USA, who revealed that the anxiety level was reduced from moderate to a mild level after the implementation of PMR technique. Other study done in Egypt, 2018 revealed that positive effect of progressive muscle relaxation technique on anxiety and depression (Darwesh, et al, 2018) ${ }^{(26)}$.

Many studies reported that progressive muscle relaxation may benefit people with certain health problems. According to the inclusion criteria of this study; all participants in the study and control groups suffered from high blood pressure i.e. more than $140 / 90 \mathrm{~mm} / \mathrm{Hg}$. After the implementation of the program, the BP of
$90 \%$ of the study subjects decreased to less than $140 / 90 \mathrm{~mm} / \mathrm{Hg}$; and only 3 elders $(10 \%)$ had still high blood pressure (table 3,4). This indicates the positive effect of the PMR in reducing BP. Other study done by (Zaho L. 2012) $)^{(27)}$, showed that progressive muscle relaxation improved quality of life and reduced blood pressure among people with heart disease.

The program also succeeded to relieve stress among elders (table 3,4); these results are congruent with those of other studies done by Kumutha V, Aruna S, Poongodi R. $(2014)^{(12)}$ in India which revealed the beneficial effects of progressive muscle relaxation technique on reducing stress among elders. Other study done in Egypt, 2017 revealed that positive effect of progressive muscle relaxation technique on depression, anxiety, stress and quality of life (Ebrahem S.M, Masry S.E, 2017) $^{(28)}$.

\section{Conclusion}

Based on the results of the present study it can be concluded that: PMR proved to be significantly effective in decreasing levels of stress, anxiety and blood pressure among institutionalized elders.

\section{Recommendations}

The main recommendations are:

- In service training of caregivers elderly homes about the benefits and technique of PMR.

- The gerontological nurse should teach, encourage and motivate elders to perform PMR. 
Table (1): Distribution of elders in the study and control groups according to their sociodemographic characteristics

\begin{tabular}{|c|c|c|c|c|c|}
\hline \multirow{2}{*}{\multicolumn{2}{|c|}{ Socio-demographic characteristics }} & \multicolumn{2}{|c|}{ Study } & \multicolumn{2}{|c|}{ Control } \\
\hline & & \multirow{2}{*}{$\frac{\mathbf{N}=\mathbf{3 0}}{12}$} & \multirow{2}{*}{$\begin{array}{c}\% \\
40.0\end{array}$} & \multirow{2}{*}{$\frac{\mathbf{N}=\mathbf{3 0}}{3}$} & \multirow{2}{*}{$\frac{\%}{10.0}$} \\
\hline Age (in years) & $60-$ & & & & \\
\hline & $70-$ & 14 & 46.7 & 16 & 53.3 \\
\hline & $80-89$ & 4 & 13.3 & 11 & 36.7 \\
\hline & & \multicolumn{2}{|c|}{ Mean $=72.3 \pm 4.64$} & \multicolumn{2}{|c|}{ Mean $=77.6 \pm 3.93$} \\
\hline \multirow[t]{2}{*}{ Sex } & \multirow{2}{*}{$\begin{array}{l}\text { Female } \\
\text { Male }\end{array}$} & 20 & 66.7 & 18 & 60.0 \\
\hline & & 10 & 33.3 & 12 & 40.0 \\
\hline \multirow[t]{5}{*}{ Education } & \multirow{5}{*}{$\begin{array}{l}\text { Illiterate } \\
\text { Read\& write } \\
\text { Primary education } \\
\text { Secondary education } \\
\text { Intermediate education }\end{array}$} & 6 & 20.0 & 7 & 23.3 \\
\hline & & 7 & 23.3 & 5 & 16.7 \\
\hline & & 5 & 16.7 & 1 & 3.3 \\
\hline & & 6 & 20.0 & 9 & 30.0 \\
\hline & & 6 & 20.0 & 8 & 26.7 \\
\hline \multirow{4}{*}{$\begin{array}{l}\text { Occupation before } \\
\text { retirement }\end{array}$} & \multirow{4}{*}{$\begin{array}{l}\text { House wife } \\
\text { Employee } \\
\text { Worker } \\
\text { Private job }\end{array}$} & 11 & 36.7 & 12 & 40.0 \\
\hline & & 8 & 26.7 & 12 & 40.0 \\
\hline & & 8 & 26.7 & 1 & 3.3 \\
\hline & & 3 & 10.0 & 5 & 16.7 \\
\hline \multirow[t]{2}{*}{ Income per month } & \multirow{2}{*}{$\begin{array}{l}\text { adequate } \\
\text { inadequate }\end{array}$} & 18 & 60.0 & 17 & 56.7 \\
\hline & & 12 & 40.0 & 13 & 43.3 \\
\hline \multirow[t]{2}{*}{ Having children } & \multirow{2}{*}{$\begin{array}{l}\text { Yes } \\
\text { No }\end{array}$} & 20 & 66.7 & 23 & 76.7 \\
\hline & & 10 & 33.3 & 7 & 23.3 \\
\hline \multirow[t]{2}{*}{$\begin{array}{l}\text { Duration of stay in the } \\
\text { home }\end{array}$} & \multirow{2}{*}{$\begin{array}{l}1<5 \text { years } \\
5 \text { years and more }\end{array}$} & 22 & 73.4 & 16 & 53.3 \\
\hline & & 8 & 26.7 & 14 & 46.7 \\
\hline
\end{tabular}

Table (2): Distribution of elders in the study and control groups according to their clinical data

\begin{tabular}{|c|c|c|c|c|}
\hline \multirow{2}{*}{ Clinical data } & \multicolumn{2}{|c|}{ Study } & \multicolumn{2}{|c|}{ Control } \\
\hline & $\mathbf{N}=\mathbf{3 0}$ & $\%$ & $\mathbf{N}=\mathbf{3 0}$ & $\%$ \\
\hline \multicolumn{5}{|c|}{ *Presence of co-morbid diseases: } \\
\hline Cardiovascular disorders & 14 & 46.6 & 19 & 63.3 \\
\hline DM\& endocrine diseases & 9 & 30 & 5 & 16 \\
\hline Neurological diseases & 7 & 23.3 & 8 & 26.6 \\
\hline Musculoskeletal disease & 5 & 16.6 & 2 & 6.66 \\
\hline Respiratory diseases & 4 & 13.3 & 3 & 10 \\
\hline GIT diseases & 2 & 6.6 & 3 & 10 \\
\hline Renal diseases & 2 & 6.6 & 0 & 0.0 \\
\hline Hematological diseases & 14 & 46.6 & 19 & 63.3 \\
\hline \multicolumn{5}{|l|}{ *Medication taken: } \\
\hline Hypoglycemic drugs & 14 & 23.4 & 19 & 31.7 \\
\hline Anticoagulant & 9 & 15.0 & 11 & 18.3 \\
\hline Vitamins & 8 & 13.3 & 4 & 6.7 \\
\hline Cortisol\& hormones & 7 & 11.6 & 4 & 6.7 \\
\hline Benzodiazepine & 5 & 8.3 & 3 & 5.0 \\
\hline Liver support & 4 & 6.7 & 3 & 5.0 \\
\hline Vasodilators & 3 & 5.0 & 2 & 3.3 \\
\hline Analgesics & 2 & 3.3 & 5 & 8.3 \\
\hline Respiratory drugs & 1 & 1.7 & 0 & 0.0 \\
\hline
\end{tabular}

*Multiple responses were given $\quad$ N.B: all elders in the study and control groups suffer from high BP. 
Progressive Muscle Relaxation, Elders' Blood Pressure, Anxiety, Stress

Table (3): Comparison between elders in the study and control groups according to their blood pressure, anxiety, and stress levels before and after implementation of the Progressive muscle relaxation technique

\begin{tabular}{|c|c|c|c|c|c|c|c|c|c|c|c|}
\hline \multirow{3}{*}{ Item } & & \multicolumn{4}{|c|}{ Study group } & \multirow{3}{*}{$\begin{array}{c}\text { FET } \\
\text { P }\end{array}$} & \multicolumn{4}{|c|}{ Control group } & \multirow{3}{*}{$\begin{array}{c}\text { FET } \\
\mathrm{P}\end{array}$} \\
\hline & & \multicolumn{2}{|c|}{ Before } & \multicolumn{2}{|c|}{ After } & & \multicolumn{2}{|c|}{ Before } & \multicolumn{2}{|c|}{ After } & \\
\hline & & $\mathrm{N}_{0}=30$ & $\%$ & $\mathrm{~N}_{0}=30$ & $\%$ & & $\mathrm{~N}_{0}=30$ & $\%$ & $\mathrm{~N}_{0}=30$ & $\%$ & \\
\hline \multirow[t]{2}{*}{ Blood Pressure } & BP value more than $140 / 90$ & 30 & 100.0 & 3 & 10.0 & $0.000^{*}$ & 30 & 100.0 & 24 & 80.0 & $1.000 *$ \\
\hline & BP value less than $140 / 90$ & 0 & 0.0 & 27 & 90.0 & 27.149 & 0 & 0.0 & 6 & 20.0 & $0.000 *$ \\
\hline \multirow[t]{2}{*}{ Anxiety level } & Mild Anxiety (score 0 - 21) & 17 & 56.7 & 23 & 76.7 & 2.700 & 18 & 60.0 & 16 & 53.3 & 1.158 \\
\hline & Moderate Anxiety (score 22- 35) & 13 & 43.3 & 7 & 23.3 & 0.100 & 12 & 40.0 & 14 & 46.6 & 0.561 \\
\hline \multirow[t]{2}{*}{ Stress level } & Mild Stress ( score 0 -18) & 6 & 20.0 & 8 & 26.7 & 5.360 & 6 & 20 & 0 & 0.0 & 4.472 \\
\hline & Moderate Stress ( score 19-37) & 24 & 80.0 & 22 & 73.3 & 0.069 & 24 & 80.0 & 29 & 96.7 & 0.107 \\
\hline
\end{tabular}

*Significant at $P \leq 0.05$ 
Progressive Muscle Relaxation, Elders' Blood Pressure, Anxiety, Stress

Table (4): Relation between mean scores of BP., anxiety and stress levels of elders in the study and control groups after the implementation of the PMR

\begin{tabular}{|l|c|c|c|}
\hline \hline Item & Study (30) & Control (30) & $\mathrm{p}$ \\
\hline Blood Pressure (systolic) & $\underline{130.17 \pm 6.884}$ & $\underline{144.83 \pm 6.363}$ & $* 0.000$ \\
\hline Anxiety level & $83.00 \pm 9.523$ & $96.83 \pm 7.484$ & \\
\hline Stress level & $15.03 \pm 8.708$ & $22.53 \pm 8.148$ & $* 0.001$ \\
\hline \hline
\end{tabular}

*Significant at $P \leq 0.05$

Table (5): Relation between age and levels of Blood pressure, anxiety and stress among study and control groups after implementation of the program

\begin{tabular}{|l|c|c|c|c|c|c|c|c|c|}
\hline \hline \multirow{2}{*}{$\begin{array}{l}\text { Age } \\
\text { In years }\end{array}$} & \multicolumn{3}{|c|}{ Blood Pressure } & \multicolumn{3}{c|}{ Anxiety level } & \multicolumn{3}{c|}{ stress level } \\
\cline { 2 - 11 } & Study & Control & $\mathrm{p}$ & Study & Control & $\mathrm{p}$ & Study & Control & $\mathrm{p}$ \\
\hline $60-$ & $\frac{128.7 \pm 6.7}{80.8 \pm 10.8}$ & $\frac{150 \pm 0}{93.3 \pm 5.77}$ & $0.007 *$ & $16 \pm 9.4$ & $20 \pm 8.6$ & 0.383 & $20.9 \pm 7.7$ & $25.33 \pm 2.5$ & 0.169 \\
\hline $70-$ & $\frac{130 \pm 7.07}{84.2 \pm 8.5}$ & $\frac{145.31 \pm 6.4}{99.1 \pm 5.8}$ & $0.000 *$ & $13.5 \pm 9.1$ & $23.4 \pm 8.9$ & $0.009 *$ & $20.6 \pm 7.8$ & $28 \pm 5.4$ & $0.004 *$ \\
\hline $80-89$ & $\frac{135 \pm 5.7}{85 \pm \pm 10}$ & $\frac{142.7 \pm 6.4}{94.5 \pm 9.3}$ & 0.062 & $17.5 \pm 5.1$ & $21.9 \pm 7.3$ & 0.325 & $23.75 \pm 3.86$ & $25.9 \pm 5.2$ & 0.513 \\
\hline \hline
\end{tabular}

*Significant at $P \leq 0.05$ 
Progressive Muscle Relaxation, Elders' Blood Pressure, Anxiety, Stress

Table (6): Relations between sex and levels of blood pressure, anxiety and stress among study and control groups after implementation of the program

\begin{tabular}{|c|c|c|c|c|c|c|c|c|c|}
\hline \multirow{2}{*}{ Sex } & \multicolumn{3}{|c|}{ Blood Pressure } & \multicolumn{3}{|c|}{ Anxiety level } & \multicolumn{3}{|c|}{ Stress level } \\
\hline & Study & Control & $P$ & Study & Control & $p$ & Study & Control & $p$ \\
\hline \multirow{2}{*}{ Male } & $\underline{129.5 \pm 6.8}$ & $\underline{146.5 \pm 6.7}$ & & & & & & & \\
\hline & $\overline{78 \pm 6.32}$ & $\overline{97.5 \pm 6.34}$ & $0.000^{*}$ & $13.6 \pm 8.3$ & $22.2 \pm 8.1$ & $0.049 *$ & $20.7 \pm 6.32$ & $26.7 \pm 4.1$ & $0.007 *$ \\
\hline Female & $\frac{130.5 \pm 7.1}{85.5 \pm 9.9}$ & $\frac{144 \pm 6.1}{96.5 \pm 8.1}$ & $0.000^{*}$ & $15.7 \pm 8.98$ & $22.7 \pm 8.3$ & $0.019^{*}$ & $21.35 \pm 7.8$ & $27.1 \pm 5.6$ & $0.013^{*}$ \\
\hline
\end{tabular}

*Significant at $P \leq 0.05$

Table (7): Relation between education and levels of blood pressure, anxiety and stress among study and control groups after implementation of the program

\begin{tabular}{|c|c|c|c|c|c|c|c|c|c|}
\hline \multirow{2}{*}{ Education } & \multicolumn{3}{|c|}{ Blood Pressure } & \multicolumn{3}{|c|}{ Anxiety level } & \multicolumn{3}{|c|}{ stress level } \\
\hline & Study & Control & $\mathrm{p}$ & Study & Control & $\mathrm{p}$ & Study & Control & $\mathrm{p}$ \\
\hline \multirow{2}{*}{ Illiterate } & $129.1 \pm 9.1$ & $144.2 \pm 5.3$ & & & & & & & \\
\hline & $83.33 \pm 8.1$ & $98.5 \pm 8.9$ & $0.010^{*}$ & $17.1 \pm 7$ & $23.8 \pm 9.5$ & 0.147 & $19.6 \pm 3.5$ & $26.14 \pm 4.9$ & $0.042 *$ \\
\hline \multirow{2}{*}{ Read and write } & $\underline{128.5 \pm 6.9}$ & $\underline{141 \pm 7.4}$ & & & & & & & \\
\hline & $87.1 \pm 13.8$ & $98 \pm 13.1$ & $0.022 *$ & $16.4 \pm 9.8$ & $22.2 \pm 6$ & 0.289 & $22.1 \pm 8.8$ & $25.8 \pm 5$ & 0.29 \\
\hline Secondary & $\frac{130.8 \pm 6.6}{80 \pm 8.9}$ & $\frac{144.4 \pm 5.8}{97.2 \pm 4.4}$ & $0.003^{*}$ & $9.1 \pm 5.8$ & $20.11 \pm 9.2$ & 0.033 & $20.8 \pm 7.4$ & $27.4 \pm 5.4$ & 0.076 \\
\hline Intermediate & $\frac{130 \pm 6.32}{80 \pm 8.9}$ & $\frac{147.5 \pm 7.1}{93.7 \pm 5.2}$ & $0.003^{*}$ & $20.3 \pm 10.98$ & $25.2 \pm 7.2$ & 0.477 & $23.7 \pm 6.2$ & $27.7 \pm 6$ & 0.243 \\
\hline
\end{tabular}

*Significant at $P \leq 0.05$ 


\section{References}

1. Morton A. Lieberman PD. Institutionalization of the Aged: Effects on Behavior. Journal of Gerontology. July 1999; Volume 24 (Issue 3).

2. ElHusseni S. Factors related to self care capabilities among institutionalized elders. Unpublished master thesis: Alexandria university; 2008.

3. Sridevi G. Death Anxiety, Death Depression, Geriatric Depression and Suicidal Ideation among Institutionalized and Non-Institutionalized Elders. International Journal of Scientific. 2014; Volume 4.

4. Najafi Ghezeljeh T, Kohandany M, Oskouei FH, Malek M. The effect of progressive muscle relaxation on glycated hemoglobin and healthrelated quality of life in patients with type 2 diabetes mellitus. Applied nursing research: ANR. 2017 Feb; 33:142-8. PubMed PMID: 28096008.

5. Kemp JMMaBJ. Quality of Life in Assisted Living Homes. Journal of Gerontology. 2000; Vol. 55B, No. 2:P117-P27.

6. Neil Ischneiderman GI. STRESS AND HEALTH: Psychological, Behavioral, and Biological Determinants. Author manuscript Journal. 2016; 2(1):607-28.

7. Abdel Wahed W. Prevalence and associated factors of stress, anxiety among Egyptian elderly Egypt. Journal of Medicine 2015; 1(2):21-56.

8. Ali SA ESI, Taher E, Zyada F. Prevalence and predictors of depression and anxiety among the elderly population living in geriatric homes in Cairo, Egypt. J Egypt Public Health Assoc 2015;89(3):127-35.

9. Holger Cramer RL, Jost Langhorst. Characteristics of patients with internal diseases who use relaxation techniques as a coping strategy. Complementary Therapies in Medicine J. 2013; 21 (5):481-6.

10. de Lorent L, Agorastos A, Yassouridis A, Kellner M, Muhtz C. Auricular Acupuncture Versus Progressive Muscle Relaxation in Patients with Anxiety Disorders or Major Depressive Disorder: A Prospective Parallel Group Clinical Trial. J Acupunct Meridian Stud. 2016 Aug; 9(4):191-9. PubMed PMID: 27555224.

11. Zhao L, Wu H, Zhou X, Wang Q, Zhu W, Chen J. Effects of progressive muscular relaxation training on anxiety, depression and quality of life of endometriosis patients under gonadotrophinreleasing hormone agonist therapy. European Journal of Obstetrics \& Gynecology and Reproductive Biology 2016; 162(2):211-5.

12. Kumutha V DAS, Poongodi R. Effectiveness of Progressive Muscle Relaxation Technique on Stress and Blood Pressure among Elderly with Hypertension. IOSR Journal of Nursing and Health Science. 2014; 3 (4):101-25.

13. Lachine O. THE EFFECT OF NURSING INTERVENTION PROGRAM ON THE LOELINESS EXPERINCED BY ELDERLY PEOPLE: University of Alexandria; 1990.

14. Peciuliene I, Perminas A, Gustainiene L, Jarasiunaite G. Effectiveness of Progressive Muscle Relaxation and Biofeedback Relaxation in Lowering Physiological Arousal among Students with Regard to Personality Features. Procedia Social and Behavioral Sciences. 2015; 205:22835.

15. Carver ML, O’Malley M. Progressive muscle relaxation to decrease anxiety in clinical simulations. Teaching and Learning in Nursing. 2015; 10(2):57-62.

16. Beck AT EN, Brown G, Steer A. An inventory for measuring clinical anxiety: Psychometric prosperities. Journal of consulting and clinical psychology 1988; 56:893-97.

17. Hellmi. L. Impact of applying foot massage on physiological and psychological status among critically ill patients. Faculty of nursing, Alexandria University; 2012.

18. Cohen-Fridel S, Bodner E, Shrira A, Bergman YS, Grossman ES. The interaction between aging and death anxieties predicts ageism. Personality and Individual Differences J. 1983; 86:15-9.

19. Hussein $H$. The effect of support group sessions on stress and burnout of caregivers of institutionalized elders. Unpublished dissertation: Alexandria University, Faculty of Nursing; 2013.

20. DG. B. Stress and anxiety in late life. Geriatric Mental Health Care J. 2003; 58:249-65.

21. Carmen P. McLean AA, Brett T. Litz, and Stefan G. Hofmann. Gender Differences in Anxiety Disorders: Prevalence, Course of Illness, Comorbidity and Burden of Illness. PMC Journals. 2012 Aug 1; 45(8):1027-35.

22. Fiske A GM, Pedersen NL. . Stress and anxiety symptoms and aging: The effects of illness and non-health related events. Gerontol B Psychol Sci Soc Sci J. 2003; 58:320-8.

23. Caron B. NPaGM. Relation between income adequacy and levels of stress and anxiety. Mayo Clinic women's healthsource. 2011; 3(4).

24. Jone zunzunequi $\mathrm{S}$, Amit Bergman, Yoav S. Cohen-Fridel, Sara Grossman, Ephraim S. Institutionalizing the Elderly - Reasons, Advantages and Disadvantages 2001. http://www.seniorhealth365.com/2011/12/03/instit utionalizing-the-elderly-reasons-advantages-anddisadvantages/l. (Retrieved on: $19^{\text {th }}$. May, 2017).

25. Burckhardt $\mathrm{C} \mathrm{HB}$. Nursing strategies and quality of life outcomes: A systematic Review. Vard I Norden. 2003; 23(1):4-9.

26. Darweesh A, Sayied, M., Ahmed, Z., Khallaf, S., Khalifa,S. Effect of Relaxation Training Techniques and Psychoeducational Program on Depression and Anxiety among Cancer Patients in Assiut, Egypt. Journal of Nursing and Health Science. 2018; 7(4), 70-77.

27. Zhao L, Wu, H., \& Zhou, X. Effects of progressive muscular relaxation training on anxiety, depression and quality of life of endometriosis patients under gonadotrophinreleasing hormone agonist therapy. Journal of Obstetrics \& Gynecology and Reproductive Biology. 2016; 162(2), 211-215.

28. Ebrahem S, Masry, S. Effect of relaxation therapy on depression, anxiety, stress and quality of life among diabetic patients in Menoufia, Egypt. . Journal of Nursing and Health Science. 2017; 5(2), 40- 49 . 